\title{
Toxicovigilance: the misuse of psychotropic drugs in Morocco. Results of a survey conducted in Casablanca
}

\author{
Abdelouahab Moussadak ${ }^{1}$, Hamid Farhane ${ }^{2}$, Brahim Benaji ${ }^{3}$, Hind Bouzoubaa ${ }^{4}$, Imad Houti ${ }^{1}$, Fatima El Omari ${ }^{5}$, Jallal \\ Toufiq $^{5}$ and Nadia Aadil ${ }^{1}$ \\ 1. Pharmacology and Toxicology group research-Department of Biology-Faculty of Sciences Ain Chock-UH2-Casablanca, Morocco. \\ 2. Anthropogenic Sciences and Biotechnologies group research-Department of Biology-Faculty of Sciences-UCD-El Jedida, Morocco. \\ 3. Group Research of Biomedical Engineering and Pharmaceuticals Sciences-National Graduate School of Arts and Crafts (ENSAM)- \\ Mohammed V University Rabat, Morocco \\ 4. Metabolism, nutrition and toxicology group research-Department of Biology-Faculty of Sciences Ben M'sik-UH2 Casablanca, Morocco. \\ 5. Moroccan Observatory of Drugs and Addictions
}

Correspondence: nadia.aadil@univh2.ac.ma

\begin{abstract}
In Morocco, there are very few studies on the use of drugs and even less on psychotropic medicines (MPSYC). In this study we identified the misuse of MPSYC and their sources of supply in order to determine their modes of consumption and also assess the consumers health status. Methods. An anonymous survey of 500 MPSYC consumers was conducted in Casablanca. Data entry and statistical analysis were carried out using SPSS 25.0 software.Results: 500 participants in the survey were poly-drug users of MPSYC with an average of $4.13 \pm 0.007$ ( \pm SEM) drugs per user. The most misused MPSYC are Clonazepam, Diazepam, Nordazepam and Tramadol with respective prevalences of $96.80 \%, 82 \%, 55.60 \%$ and $47.80 \%$. A statistical analysis showed that clonazepam ( $p=0.047)$ and tramadol $(p=0.005)$ are prevalent in the street market. $54.20 \%$ of survey participants use MPSYC once a week while $39.80 \%$ of them use it twice a week. The same statistical analysis revealed that taking several MPSYC lead to an increase of ingested doses $(p<0.001)$ and alcohol consumption $(p=0.003)$. $96.40 \%(n=482)$ of the participants declared that they had experienced discomfort misusing the medicine.
\end{abstract}

keywords: psychotropic drugs, misuse, drugs, prevalence, consumption, access, health

\section{Introduction}

As a result of innovations in drug production and trafficking, the global market has grown significantly, with the rate of drug use rising from $4.8 \%$ of the world's population in 2009 to $5.3 \%$ in 2018 [1]. In addition to plant-based substances such as cannabis, cocaine and heroin, hundreds of increasingly pure and potent synthetic drugs have been added. There has also been a quick increase in the nonmedical use of certain drugs.

In the most of cases, psychotropic drugs are used for therapeutic and self-medication, reasons rather than for addiction issues. The disturbance of alertness and addiction, that some of these drugs may induce, are at the origin of problematic and risky uses, that we name diverted use. Misuse can be considered to occur when the user of the medicine is off the medical framework, with objectives other than treatment. Thus, The user who consumes a drug that has not been prescribed, will most likely resell it or hand it to other users. The dosages or the frequency of administration are not respected and sometimes even the administration route [2].

In the context of the overuse of psychotropic drugs, the World Drug Report 2018 reported that the non-medical use of benzodiazepines and related substances is one of the main problems related to drug use in some 60 countries [3]. 
In Morocco, the prevalence of drug use among the general population aged 15 years and over was $4.1 \%$ in 2003. This use is dominated by cannabis, with $3.93 \%$, followed by sedatives with a prevalence of $0.18 \%$ of the population [4]. Several surveys carried out in schools have reported prevalence's in favour of experimental drug use. The Medspad studies carried out in 2009, 2013 and 2017 among high school students showed a lifetime use of psychotropic drugs without medical advice or prescription of $4.3 \%, 5.4 \%$ and $5 \%$ respectively [5- 6- 7]. Another study carried out in the North-Central region of Morocco among 3020 students showed that $1.8 \%$ of the students questioned used psychotropic drugs without a medical prescription [8], while in 2020 , another study in the Beni Mellal region showed lifetime consumption prevalence's between 1 and $2 \%$ for girls and 5 and $6 \%$ for boys [9].

Concerning the misuse of psychotropic drugs, it is important to distinguish between widespread use in the general population, such as among young people in general and schoolchildren in particular, and the use that does not comply with therapeutic standards, such as among drug rusers. It is also important to emphasise that almost all surveys and studies on the misuse of psychotropic drugs focuses on the overuse of prescribed drugs for self-medication, recreational use or abuse. The use of illicitly manufactured, falsified or substandard drugs, which are the subject of global or regional trafficking movements, remains very little explored and documented

The extent of the use of illicit medicines is, however, difficult to assess, since this activity is illegal and therefore hidden. In 2019, the INCB report reported nonmedical use of high-potency Tramadol tablets in excess of $200 \mathrm{mg}$ in West, Central and North Africa. The amount of Tramadol seized has increased significantly, peaking at more than 125 tons intercepted worldwide in 2017, most of which was in Africa. In 2019, the non-medical use of tablets with high Tramadol content continues to be reported in Egypt, the United Arab Emirates and the State of Palestine [10].

The use of psychotropic drugs in the general population, as well as non-compliant use among drug users, remains poorly studied and documented in Morocco. The objective of this study is to identify psychotropic drugs diverted from their uses in a group of poly-consumers of psychoactive substances in Casablanca, to define the modalities of their consumption and to assess their impact on health.

\section{Methods}

\section{Study design}

This is a cross-sectional study targeting diverted MPSYC users, conducted at two non-specialised social structures in the city of Casablanca, between August 2018 and August 2019. To be included in the study, participants must have misused a psychotropic drug at least once in their lifetime.

\section{Sampling method}

The sample was constructed using non-probability sampling, following the so-called "snowball" method. It is a method that makes it possible to reach hidden or hard-to-reach populations. The method consists of asking the respondent to introduce one or more of his or her acquaintances who are also users of psychotropic drugs to the interviewer. In order to avoid a network effect at the level of the study group, each respondent should not exceed three recruitments. Seven trained interviewers administered an anonymous questionnaire to recruited participants at the two study sites and to their acquaintances who agreed to participate in the survey. This sampling plan enabled us to obtain a 500 users sample of psychotropic drugs outside the medical setting. The sample size is much larger than that calculated on the basis of the national prevalence of drug addiction in the general population (4.1\%) [4], the number of inhabitants of Casablanca in $2018(6,688,258$ inhabitants) [11], a confidence level of $95 \%$, a margin of error of $5 \%$ and a percentage value of $0.5(\mathrm{~N}=384)$.

\section{Data collection}

Participation in the study was entirely voluntary after a clear explanation of its objectives and guaranteed confidentiality of the answers. Data were collected using a questionnaire in Arabic, consisting of 36 closed questions administered face-to-face by an interviewer. The questions were divided into four sections; sociodemographic background, use of psychoactive substances, misuse of psychotropic drugs and selfassessment of health status.

\section{Statistical analysis.}

The data entry stage began after all responses had been collected. Data were entered into MS Windows Excel 
(Microsoft Corporation, version 2016) in code form and then transferred to Statistical Package for Social Sciences SPSS (IBM SPSS statistics for Window version 25), statistical analysis was carried out using the latter software. Categorical variables were expressed in terms of numbers and percentages and quantitative variables in terms of means $\pm \mathrm{SE}$. The student's t-test was used to compare the means of the number of drugs consumed over the 30 days of the variables studied, and the Chi-2 test was used in the univariate associations of the main drugs identified with their sources of access. The multivariate comparison of the means of the number of drugs consumed over 30 days with the different explanatory variables was carried out by multiple linear regression. All statistical tests were performed using a significance level of $P<0.05$.

\section{Results}

\section{Socio-demographic characteristics}

The 500 people who took part in the study answered almost all the questions, with a response rate of $98 \%$. Within the studied group, there was a clear male predominance with $83 \%$ of the respondents being men and $17 \%$ being women. The most represented age group was $15-25$ years old, with a prevalence of $50.40 \%$, while only $12 \%$ of the participants were still in school. Three out of four people $(75.4 \%)$ have secondary education, $40 \%$ are unemployed and $68.6 \%$ still live in the parental home. The monthly family income remains below $300 \$$ for $36.57 \%$ of the participants and $33.76 \%$ are from middleincome families (Table I).

Table I. Socio-demographic characteristics of the study participants $(\mathrm{N}=500)$

\begin{tabular}{|l|l|r|}
\hline & N & \% \\
\hline Gender & & \\
Wan & 415 & 83,00 \\
Aoman & 85 & 17,00 \\
\hline $15-25$ & & \\
$26-40$ & 252 & 50,40 \\
$41-60$ & 217 & 43,40 \\
$61-75$ & 30 & 6,00 \\
\hline Social situation & 1 & 0,20 \\
Studies & & \\
Job & 60 & 12,00 \\
unemployment & 241 & 48,20 \\
\hline
\end{tabular}

\begin{tabular}{|l|l|r|}
\hline School levels & & \\
Illiterate & 15 & 3,00 \\
Primary school & 51 & 10,20 \\
Middle school & 136 & 27,20 \\
High school & 191 & 38,20 \\
University & 57 & 11,40 \\
Professional training & 50 & 10,00 \\
\hline Marital status & & \\
Single & 338 & 67,60 \\
Married & 102 & 20,40 \\
Divorced & 60 & 12,00 \\
\hline Housing situation & & \\
Without & 38 & 7,60 \\
Personal & 119 & 23,80 \\
Parental & 343 & 68,60 \\
\hline Socioeconomic levels & & \\
$<300 \$$ & 143 & 36,57 \\
300\$<-<1000\$ & 118 & 30,18 \\
>1000\$ & 14 & 3,58 \\
I don't know & 116 & 29,67 \\
\hline
\end{tabular}

\section{Consumption of psychoactive substances}

Apart from the psychotropic drugs under study, the results showed high prevalences of consumption in the last 30 days for tobacco (96.33\%), alcohol (74.03\%) and cannabis (90.16\%). Other illicit drugs were also used in the last 30 days preceding the survey, with a prevalence of $75.86 \%$ for ecstasy, $36.36 \%$ for cocaine and $26.67 \%$ for heroin. The group studied is largely made up of multiple SPA users (Mean \pm ES: $4.48 \pm 0.006$ ), recruited in two social structures dedicated to supporting drug users.

\section{Misuse of psychotropic drugs}

Given that the main inclusion criterion for the study is the use of psychotropic drugs (MPSYC) in the context of misuse, the group studied showed a regular consumption, as shown by the prevalence over 12 months (94.00\%) and over the 30 days (91.40\%) preceding the survey. The 500 participants in the survey are poly-users of MPSYC with an average of $4.13 \pm 0.07$ ( \pm SEM) drugs per user. The number of MPSYC consumed per participant is significantly affected by gender, age, level of education and socio-economic level (Table II).

Table II. Average ( \pm ES) number of medicines used according to some socio-demographic criteria

\begin{tabular}{|c|c|c|c|c|}
\hline \multicolumn{5}{|c|}{ Number of MPSYC consumed over $\mathbf{3 0}$ days } \\
\hline & $\mathrm{N}$ & Mean & ES & P-value \\
\hline Woman & 85 & 3,71 & 0,144 & 0,005 \\
\hline
\end{tabular}




\begin{tabular}{|c|c|c|c|c|c|}
\hline $\begin{array}{l}\mathrm{G} \\
\mathrm{e} \\
\mathrm{n} \\
\mathrm{d} \\
\mathrm{er}\end{array}$ & Man & 415 & 4,22 & 0,079 & \\
\hline \multirow{2}{*}{$\begin{array}{l}\text { ge } \\
\text { gr }\end{array}$} & $15-25$ & 252 & 4,33 & 0,105 & \multirow[t]{7}{*}{0,014} \\
\hline & $26-40$ & 217 & 3,97 & 0,100 & \\
\hline 0 & \multirow[t]{5}{*}{$41-60$} & \multirow[t]{5}{*}{30} & \multirow[t]{5}{*}{3,67} & \multirow[t]{5}{*}{0,216} & \\
\hline $\begin{array}{l}\text { u } \\
\text { ps }\end{array}$ & & & & & \\
\hline (y & & & & & \\
\hline ea & & & & & \\
\hline 1 & & & & & \\
\hline \multirow{6}{*}{$\begin{array}{l}\text { Sc } \\
\text { h } \\
\text { o } \\
\text { ol } \\
\text { le } \\
\text { ve } \\
\text { Is }\end{array}$} & Illiterate & 15 & 4,13 & 0,307 & \multirow[t]{6}{*}{0,025} \\
\hline & Primary & 51 & 4,37 & 0,204 & \\
\hline & Middle & 136 & 4,23 & 0,146 & \\
\hline & High & 191 & 4,29 & 0,114 & \\
\hline & University & 57 & 3,54 & 0,184 & \\
\hline & $\begin{array}{l}\text { Professional } \\
\text { training }\end{array}$ & 50 & 3,74 & 0,193 & \\
\hline & $<300 \$$ & 143 & 4,37 & 0,130 & \multirow[t]{4}{*}{0,001} \\
\hline & $\begin{array}{l}300<- \\
<1000 \$\end{array}$ & 118 & 3,77 & 0,135 & \\
\hline \multirow[b]{2}{*}{$\begin{array}{c}\text { ec } \\
\text { o } \\
\mathrm{n} \\
\mathrm{o} \\
\mathrm{m} \\
\text { ic } \\
\text { le } \\
\text { ve } \\
\text { Is }\end{array}$} & $>1000 \$$ & 14 & 4,50 & 0,429 & \\
\hline & $\begin{array}{l}\text { I Don't } \\
\text { know }\end{array}$ & 116 & 4,62 & 0,167 & \\
\hline
\end{tabular}

The MPSYCs most concerned by this misuse have a prevalence of over $40 \%$, and are Clonazepam (Rivotril ${ }^{\circledR}$ ) and Diazepam (Valium ${ }^{\circledR}$ ), followed by Nordazepam (Nordaz ${ }^{\circledR}$ ) and Tramadol. A second group of MPSYCs with prevalences between 10 and $25 \%$ was also identified, including Levomepromazine (Nozinan $\left.{ }^{\circledR}\right)$, Lorazepam $\left(\right.$ Temesta $\left.^{\circledR}\right)$, Bromazepam (Lexomil $\left.{ }^{\circledR}\right)$, Trihexyphenidyl $\left(\right.$ Artane $\left.^{\circledR}\right)$ and Olanzapine (Ranozyp $\left.{ }^{\circledR}\right)$. Codeine (Codoliprane ${ }^{\circledR}$ and Neocodion ${ }^{\circledR}$ syrup) is an analgesic drug, also concerned by this misuse because of its psychotropic component (17.84\%) (Figure 1).

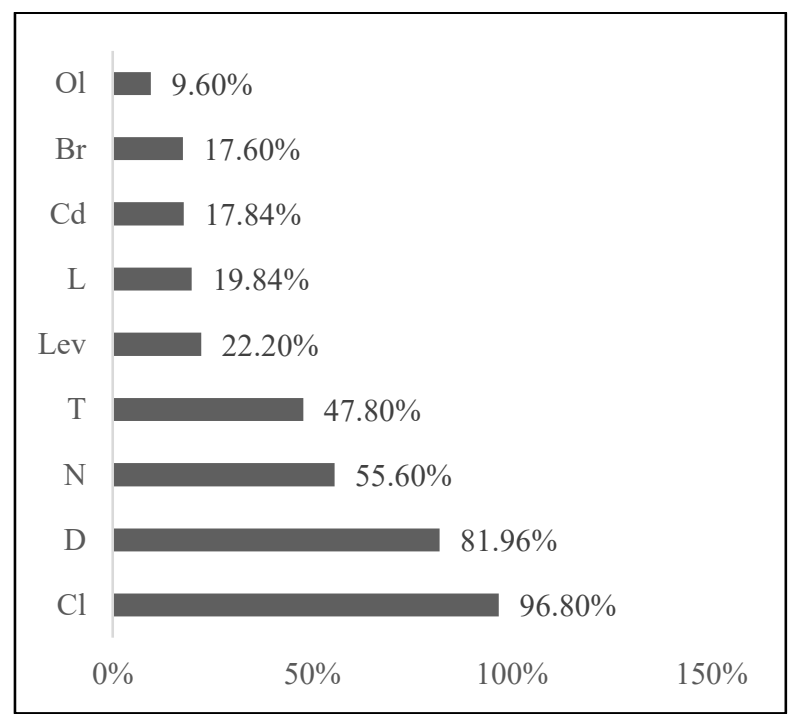

Figure 1. Prevalence of MPSYC most affected by misuse, within the study group (CL:Clonazepam, D:Diazepam, N:Nordazepam, T:Tramadol, Lev:Levomepromazine, L:Lorazepam, Cd:Codeine, Br: Bromazepam, Ol : Olanzapine)

93.40\% of the users interviewed stated that they had obtained PSYCs from vendors (street market), 68.80\% from friends and family and only $5.60 \%$ had ever used a falsified prescription. $32.40 \%$ of participants reported having used prescribed PSYCs outside the medical setting. Statistically significant associations were observed between the source of supply "seller" (street market) on the one hand, and clonazepam ( $p=0.047)$ and tramadol $(p=0.005)$ on the other. It is the same case for Lorazepam ( $p=0.012$ ), eventhough its frequency of use in the sample is relatively low (19.84\%). Relative supply is significantly related to Nordazepam $(p<0.001)$ and tramadol $(p=0.041)$, but also to Olanzapine $(p=0.003)$, Lorazepam(0.002) and codeine $(p=0.05)$. The use of falsified prescriptions was significantly associated with the misuse of two analgesic drugs: Tramadol $(p=0.01)$ and Codeine $(p=0.041)$. The latter result could be explained by a less tight dispensing of analgesics, compared to MPSYC which are restricted and controlled.

The average number of PSYC consumed per user is significantly higher among those who declare declared obtaining their supplies from sellers $(\mathrm{N}=467)$ rather than from other sources ( $N=33$ ) (Source sellers: $4.20+0.073$ Vs Other sources: $3.24+0.230 ; p=0.001)$. This result is also confirmed by a multivariate analysis involving other explanatory variables (Table III). 
The frequency of weekly consumption of MPSYC in this context of misuse is once a week for $54.20 \%$ of the participants and twice a week for $39.80 \%$ of them. Only $3.20 \%$ of respondents reported a more than twice a week use. The frequency of weekly consumption did not show a significant association with age and gender.

Table III. Multivariate linear regression analysis for factors related to the number of MPSYCs consumed by participants.

\begin{tabular}{|l|l|l|l|}
\hline Variable & Bêta & $\mathrm{t}$ & $\begin{array}{l}\mathrm{P} \\
\text {-value }\end{array}$ \\
\hline Socio-demographic criteria & & & \\
\hline Gender & 0,145 & 3,039 & $\mathbf{0 , 0 0 3}$ \\
\hline Age groups (years) & $-0,142$ & $-2,777$ & $\mathbf{0 , 0 0 6}$ \\
\hline Family situation & $-0,014$ & $-0,281$ & 0,779 \\
\hline Social situation & $-0,077$ & $-1,639$ & 0,102 \\
Housing situation & $-0,080$ & $-1,638$ & 0,102 \\
\hline School levels & $-0,086$ & $-1,737$ & 0,083 \\
\hline Socioeconomic levels & 0,080 & 1,783 & 0,075 \\
\hline Relations with the family & 0,047 & 1,013 & 0,312 \\
\hline Number of SPAs 30 days & $-0,017$ & $-0,375$ & 0,708 \\
\hline Sources of MPSYC & & & \\
\hline Seller & 0,146 & 3,211 & $\mathbf{0 , 0 0 1}$ \\
\hline Entourage & 0,069 & 1,518 & 0,130 \\
\hline Falsified prescription & 0,049 & 1,063 & 0,288 \\
\hline Number tablets /dose & 0,167 & 3,737 & $<0,001$ \\
\hline SPAs consumption & & & \\
\hline Alcohol consumption & 0,105 & 2,143 & $\mathbf{0 , 0 3 3}$ \\
\hline Cannabis consumption & 0,020 & 0,416 & 0,678 \\
\hline Ecstasy consumption & $-0,029$ & $-0,658$ & 0,511 \\
\hline
\end{tabular}

MPSYC were generally taken once a day by $91.31 \%$ of the participants, out of which $89.11 \%$ took 1 to 3 tablets per dose while $10.89 \%$ of them took more than 3 . The number of tablets ingested per dose was significantly associated with the number of MPSYC consumed, as shown by the results of multivariate linear regression $(p<0.001)$ (Table III).

Another problem associated with this misuse of MPSYC is their association with other psychoactive substances, particularly alcohol. Indeed, the average number of psychoactive substances consumed in the 30 days preceding the survey was $4.48 \pm 0.006$ per participant. The results of the multivariate linear regression analyzing the number of MPSYC and the psychoactive substances consumed by the participants showed a significant association only with alcohol ( $p=0.003)$ (Table III).
With regard to the final objective of the study, wich is the assessment of MPSYC misuse impact on health, $96.40 \%$ $(n=482)$ of the participants declared that they had experienced out of context discomfort associated with this use. These discomforts were nervous, digestive and respiratory, with respective prevalences of $86.40 \%$ $(n=432), 44.40 \%(n=222)$ and $61.80 \%(n=309)$. The results of the multivariate linear regression comparing the general feeling of discomfort with some explanatory variables, showed a significant association of the socioeconomic level $(p=0.018)$. As for the perception of the health risks incurred with the use of MPSYC, $85 \%$ of the participants declared that they were aware of them, while $15 \%$ said they knew nothing about the issues.

\section{Discussion}

In Morocco, studies carried out among populations with problematic drug use are rare. To our knowledge, all the studies carried out in this context have focused on HIV infection among injected drugs users [12]. A study carried out in 2008 in three cities in northern Morocco (Tangiers, Tetouan and Nador) showed 300 injected drugs users looked also for the use of several other psychoactive substances [2]. In comparison with this study, the male/female representativeness of our sample ( $83 \%$ men/17\% women) is relatively close to that of the sample from the three cities ( $91 \%$ men and $9 \%$ women) and almost identical to that recorded in the city of Tetouan ( $83.3 \%$ men and $16.7 \%$ women). The $15-25$ age group is more represented in our sample (50.40\%) compared to the 18-25 age group, which represents only $4 \%$ of the sample recruited in the three cities. This difference could be explained by the generally advanced age of the population of injected drugs users. In 2017, statistics from addiction care, support and prevention centres in France indicated that $80 \%$ of opioid, cocaine and other illicit drug users are aged 30 and over, with an average age of 38.5 years [13].

Apart from psychotropic drugs, the use of different psychoactive substances in our study group is very diverse, with high overall prevalences that vary greatly depending on the type of substance. The prevalence's over the last 30 days preceding the survey are $96.33 \%$ for tobacco, $74.03 \%$ for alcohol and $90.16 \%$ for cannabis. Ecstasy, cocaine and heroin are also used, with prevalence rates of $75.86 \%, 36.6 \%$ and $26.67 \%$ respectively. This is a group of poly-drug users, $98.40 \%$ of 
whom have been using drugs for more than three years. This poly-drug use was also observed in $94 \%$ of the participants in the study carried out in northern Morocco, where the prevalence of heroin, cannabis and cocaine was $97 \%, 84 \%$ and $38 \%$ respectively [2].

Concerning the psychotropic drugs which are the subject of our study, $100 \%$ of the participants have used them during their lives. The prevalence of consumption over 12 months (94\%) and over the 30 days preceding the survey $(91.4 \%)$ shows that they are regular consumers. The lifetime prevalence of benzodiazepine consumption reported by the national study is $44.7 \%$, we used it to compare our sample[2]. The average number of psychotropic drugs used by the participants in our study was significantly associated with gender and age. There is a predominance of males and a large representation of the 15-25 years old category. According to the French Observatory of Drugs and Drug Addiction, benzodiazepine misuse is proportionally more important among the youngest, men, the most precarious and the most frequent users [14].

To our knowledge, no study seeking to identify psychotropic drugs used for diverted purposes has been conducted in Morocco. Benzodiazepines are the most MPSYCThe MPSYCs most concerned by diverted use in our study. Clonazepam, Diazepam and Nordazepam are the most common, with prevalences of $96.80 \%, 81.96 \%$ and $55.60 \%$ respectively. The use of Lorazepam and Bromazepam was also mentioned by the participants, with prevalences of $19.84 \%$ and $17.60 \%$ respectively. In France, the addiction-vigilance network has identified abuse and misuse of some benzodiazepines. In 2015, the top four benzodiazepines in the ranking by diversion indicators were oxazepam, zolpidem, alprazolam, and diazepam in general practice [15]; and oxazepam, clonazepam, alprazolam, and bromazepam in specialized facilities [16]. Both surveys classified benzodiazepines according to indicators of diversion, which were illegal procurement, use of doses twice those recommended by the marketing authorization, suffering on discontinuation of the substance and use of alcohol to potentiate their effects. Despite the introduction of restrictions on the prescription of Clonazepam in France in 2011, this benzodiazepine has retained the most indicators of diversion since 2012, although it is the least consumed according to the 2015 OPPIDUM survey. The Falsified Prescription Survey (OSIAP) in 2015, also reported that Clonazepam is the leading benzodiazepine in terms of diversion indicators [17]. In Morocco, the prescription of Clonazepam is not strictly reserved for specialist doctors, as in France, but its dispensing at pharmacy facilities remains relatively supervised and secured. However, the high prevalence of this benzodiazepine reported in our study could possibly be associated with a street market, or even trafficking in this molecule. In relation to street markets, several reports have highlighted their existence in several French cities, with over-the-counter sales of psychotropic drugs mainly fuelled by the resale of prescribed drugs [18]. As for the possibility of trafficking, particularly in the case of Clonazepam, the National Observatory of Drugs and Addictions in Morocco published in its 2014 report the existence of a supposed benzodiazepine trafficking route arriving from the East [12].

In contrast, this trafficking problem is widely recognized worldwide in the case of Tramadol. This opioid analgesic, known for its non-medical use among drug users, is heavily affected by the trafficking problem in several countries. Until 2018, seizures of high-potency tablets with a dosage of more than $200 \mathrm{mg}$ remain very frequent in West, Central and North Africa. The quantities of Tramadol seized, increased significantly to peak at over 125 tons intercepted worldwide in 2017, most of which was in Africa. In 2018, Nigeria reported a seizure of 581 million high-dose Tramadol tablets and Morocco seized 45 million [19]. These data, should prompt us to question the source of access to Tramadol, which in our study has a prevalence of almost $50 \%$ and a significant association with both "Seller" and "entourage" sources of supply. With regard to the methods of consumption of MPSYC in our study, the results show that the weekly frequency of consumption is two doses per week, for $54.20 \%$ of the participants, and that the number of tablets taken, between 1 and 3 in $89.11 \%$ of cases, is significantly associated with the number of drugs consumed per user. The concomitant use of alcohol is also an issue to be considered in our study, with $74.03 \%$ of participants stating that they associate alcohol with the use of MPSYC. A significant association was also demonstrated between the average number of MPSYC consumed per user and alcohol intake. These three results confirm the diverted use of psychotropic drugs in the sample studied. In fact, misuse can be considered to occur when the user consumes a drug which has not been prescribed, does not respect the doses and frequency of intake, or combines it with alcohol [20].

The questions we asked about feelings of discomfort, possibly related to the diverted use of MPSYC, show that 
$96.40 \%$ of cases are concerned. The discomforts were generally nervous (86.40\%), respiratory (61.80\%) and digestive $(44.40 \%)$. The multivariate analysis of the feeling of discomfort showed a significant association with the socio-economic level. Precariousness in this case could be among the first factors of vulnerability, especially in an environment where access to health care is limited. The impact on health of the misuse of psychotropic drugs in the general population is very poorly documented, and even less so among drug users, who are often multiple users of psychoactive substances. The share of psychotropic drug use in treatment requests submitted by drug users in France increased by $35 \%$ between 2015 and 2017 [21]. When not prescribed, psychotropic drugs can have deleterious effects on the psychic and somatic levels, with eating disorders and antisocial disorders. Also, a statistical association between misuse and suicidal behaviors among adolescents has been demonstrated [22 ].

In a context where there is almost no data on diverted psychotropic drugs in the general population or among drug users, the results of this survey represent a first step towards wider and more in-depth studies, with the aim of understanding and identifying this scourge on a national scale. Morocco has committed over the last two decades through its national strategies, to combat addictive disorders by creating, among other things, addiction center's at the country's various university hospitals. However, there is a need for more research studies in the field to identify the origin and means of access and to understand the modes of consumption and the impact on health of psychoactive substances in general, and in particular psychotropic drugs diverted from their uses.

\section{References}

1. World Drug Report, United Nations publication, Sales No. E.20.XI.6 (2020).

2. M.Maitena and E. Langlois. "Faire face aux épreuves de la vie juvénile: l'usage détourné de médicaments psychotropes chez les jeunes.". Déviance et Société 41 , 4 (2017).

3. World Drug Report.United Nations publication, Sales No. E.14.XI.7 (2014).

4. D. Moussaoui. La santé mentale au Maroc : enquête nationale sur la prévalence des troubles mentaux et des toxicomanies. L'Encéphale 33 (2007).
5. J. Toufiq, F. El Omari, M. Sabir. Usage de drogues en milieu scolaire marocain. Rapport MedSPAD (20092010).

6. F. Elomari, M.Sabir, J. Toufiq. L'usage de drogues auprès des élèves marocains, l'enquête Scolaire. Rapport MedSPAD (2013).

7. F.El Omari,., M.Sabir, J.Toufiq. Usage de substances psychoactives auprès des adolescents scolarisés au Maroc. Rapport MedSPAD (2018).

8. B. Zarrouq, B. Bendaou, A. El Asri, S. Achour, I. Rammouz, R. Aalouane, R.B. Lyoussi, S. Khelafa, A. Bout, N. Berhil, H.Hlal, A. Najdi, C. Nejjari, K. El Rhazi. BMC Public Health. 16, 1 (2016).

9. H. El Assli, M. Merzouki., F. Chigr, A. Aimrane, M. Najimi. Children and Youth Services Review. 117 (2020).

10. UNIES, Nations. Organe international de contrôle des stupéfiants (2019).

11. A.Mallouk, H. Elhadrachi, M.E.I. Malaainine, H. Rhinane. International Archives of the Photogrammetry, Remote Sensing and Spatial Information Sciences 42, 4/W12 (2019).

12. F. El Omari, J. Toufiq, M. Sabir. L'Observatoire National des Drogues et Addictions (ONDA). Rapport annuel, Maroc (2014).

13. Observatoire français des drogues et des toxicomanies. Drogues et addictions, données essentielles. Observatoire français des drogues et des toxicomanies (2019).

14. Observatoire français des drogues et des toxicomanies. Synthèse thématique : médicaments psychotropes. Observatoire Français des Drogues et des Toxicomanies (2021).

15. Centre d'addictovigilance PACA Corse, Programme d'Observation des Pharmacodépendances En Médecine Ambulatoire - OPEMA N7. Principaux résultats. ANSM, France (2015).

16. CEIP, ANSM, OPPIDUM. Observation des Produits psychotropes Illicites ou Détournés de leur Utilisation Médicamenteuse. Principaux résultats 2015. Saint-Denis, ANSM, France (2017).

17. CEIP-A de Toulouse, Principaux résultats de I'enquête OSIAP. Ordonnances Suspectes Indicateurs d'Abus Possible 2015. Saint-Denis, ANSM, France (2017).

18. A. CADET-TAÏROU, M. GANDILHON, C. GÉROME et al. 1999-2019:les mutations des usages et de l'offre de drogues en france. Observatoire Français des Drogues et des Toxicomanies (2020). 
19. Nations Unies. OICS. Organe international de contrôle des stupéfiants (2019).

20. A. Cadet-Taïrou, E. Janssen, F.Guilbaud. Profils et pratiques des usagers reçus en CAARUD en 2019. Observatoire français des drogues et des toxicomanies (2019).

21. C. Palle, M. Rattanatray. Les centres de soins, d'accompagnement et de prévention en addictologie en 2016. Situation en 2016 et évolutions sur la période 2005-2016. Analyse des données des rapports d'activité des CSAPA. Saint-Denis, Observatoire Français des Drogues et des Toxicomanies (2018).

22. F. Beck et al. Conduites addictives chez les adolescents: usages, prévention et accompagnement. Thèse de doctorat. Institut national de la santé et de la recherche médicale (INSERM) , France (2014).

We would like to thank all the people who took part in the study, the investigators, the members of the Al Azhar association and the entire network of associations involved in the fight against drugs in Casablanca.

We would also like to thank Mr Youssef Benchekroun, Industrial Pharmacist, PhD in Pharmaceutical Sciences, for his help in entering and processing the data.

The authors declare that they have no competing interest. 